\title{
ФИТОПЛАНКТОН РЕКИ ОБЬ В РАЙОНЕ ГОРОДА СУРГУТ 1
}

\section{PHYTOPLANKTON OF THE OB RIVER IN VICINITY OF SURGUT}

\section{O. Skorobogatova \\ E. Gontazhevskaya \\ A. Moskaleva}

Summary. An ecological and floristic phytoplankton assessment of the Ob River in one of its middle course segments, located at high latitudes, was carried out. A rich algological community was observed, based on the summer and autumn field material, with the composition noticeably changed since earlier studies carried outin 1996. The top 10 families comprise more than a half, and the largest 8 genera include $33 \%$ of all observed algae.Under conditions of $\mathrm{pH}$ close to neutral, the main factor influencing the formation of species diversity, total abundance and structure of the identified phytoplankton is water temperature. Thestudy also features the floristic comparison of the $0 \mathrm{~b}$ River plankton algocenoseswith those of other large rivers: Lena, Irtysh, Dnieper, Volga. The prevalence of planktonic, widespread, oligohalobial, betamesosaprobic varieties and forms of algae, which prefer a neutral medium reaction, was revealed in the studied phytoplankton.

Keywords: species, algocenose, flora, diversity, abundance, ecology.

\section{Ввемение}

ород Сургут располагается на правом берегу реки Обь, в среднем её течении в центральной части Западно-Сибирской равнины.

По климатическим условиям район приравнен к Крайнему Северу. Климат района резко континентальный. Зима суровая, холодная, продолжительная, снежный покров сохраняется в среднем 207 дней. Лето короткое, теплое. Наблюдаются резкие колебания температуры в течение года и даже суток [12]. Речная сеть относится к бассейну Карского моря. Исследуемый участок приходится на зону тайги, где р. Обь протекает в основном по болотистой таежной равнине. В районе преобладают верховые болота, которые питаются

\author{
Скоробогатова Ольга Николаевна \\ К.б.н., дочент, Нижневартовский государственный \\ университет \\ Olnics@yandex.ru \\ Гонтажевская Екатерина Николаевна \\ Нижневартовский государственный университет \\ Москалева Анна Сергеевна \\ Нижневартовский государственный университет
}

Аннотация. Проведена эколого-флористическая оценка фитопланктона реки 0бь на одном из отрезков ее среднего течения, находящегося в высоких широтах. На основе летне-осеннего полевого материала установлено богатое альгологическое сообщество, состав которого заметно изменился при сравнении с более ранними исследованиями 1996 г. В составе ведущих 10 семейств находится более половины, а крупнейшие 8 родов включают 33\% всех выявленных водорослей. В условиях показателя $\mathrm{pH}$ близкого к нейтральному, основным фактором, влияющим на формирование видового богатства, общей численности и структуры выявленного фитопланктона является температура воды. Приведено флористическое сравнение альгоценозов планктона реки Обь с крупными реками: Лена, Иртыш, Днепр, Волга. В исследованном фитопланктоне выявлено преобладание планктонных, широко распространенных, олигогалобных, бетамезосапробных разновидностей и форм водорослей, предпочитающих нейтральную реакцию среды.

Ключевые слова: вид, альгоценоз, флора, разнообразие, численность, экология.

атмосферными осадками. Мощность торфа достигает 6-10 м. Берега реки преимущественно низкие, заболоченные, легкоразмываемые [4].

Среднее течение Оби в альгологическом плане до 1980-х годов исследовалось фрагментарно. Затем с 1979 по 1994 гг. Науменко Ю.В. были проведены многолетние исследования, касающиеся выявления видового состава, сезонной и межгодовой динамики фитопланктона и оценки качества вод р. Обь [10]. Однако обновление альгоценозов происходит каждые 3-5 лет, поэтому настоящее исследование остается весьма актуальным. Результаты исследования по зеленым хлорококковым водорослям опубликованы в 2018 г $[5,6]$. Оригинальные материалы опубликованы по зеленым водорослям [1]. 
Таблица 1. Таксономический состав выявленного фитопланктона р. Обь (г. Сургут)

\begin{tabular}{|c|c|c|c|c|c|c|}
\hline Отдел & Класс & Порядок & Семейство & Род & Вид, разновидность & Доля,\% \\
\hline Cyanobacteria & 1 & 3 & 3 & 7 & 9 & 2,8 \\
\hline Chrysophyta & 3 & 3 & 4 & 8 & 34 & 10,5 \\
\hline Bacillariophyta & 2 & 12 & 22 & 36 & 114 & 35,2 \\
\hline Euglenophyta & 2 & 2 & 3 & 9 & 60 & 18,5 \\
\hline Xanthophyta & 1 & 1 & 1 & 1 & 2 & 0,6 \\
\hline Dinophyta & 1 & 2 & 4 & 5 & 8 & 2,5 \\
\hline Cryptophyta & 1 & 1 & 1 & 1 & 2 & 0,6 \\
\hline Chlorophyta & 3 & 4 & 16 & 39 & 84 & 25,9 \\
\hline Charophyta & 1 & 1 & 3 & 5 & 11 & 3,4 \\
\hline Всего & 15 & 29 & 57 & 111 & 324 & 100 \\
\hline
\end{tabular}

\section{Материалы и методы исследования}

Исследование основано на 27 оригинальных сборах фитопланктона реки Обь, выполненных в период с июля по октябрь 2018 года, стационарным методом, 2 раза в месяц (левое, правое течение и середина), в створе города Сургут.

Изучение водорослей выполнено на зафиксированном формальдегидом материале, с доведением раствора до 4\%, и обработкой осадка гравиметрическим методом. Одновременно со сбором фитопланктона с помощью портативного pHcan 2 Wateroof измеряли температуру и активную реакцию воды.

Микроскопирование выполнено с применением световых микроскопов Nikon Elipse E200 и Primo Star Zeiss с кратным увеличением от 640 до 1600, идентификация проведена с помощью отечественных и зарубежных определителей, монографий и атласов. Диатомовые водоросли определены на постоянных препаратах, изготовленных путем помещения их створок в канадский бальзам. Освобождение створок диатомовых водорослей от органических веществ осуществлено методом холодного выжигания с помощью серной кислоты. Таксономический список выявленных водорослей, выполнен в соответствии с современными номенклатурными изменениями глобальной базы данных по водорослям [24]. Анализ таксономической структуры фитопланктона проведен с использованием методов, принятых в сравнительной флористике [8, 21].

Количественный учет клеток каждого вида проведен в камере Наджотта с перерасчетом на 1 литр пробы воды [14]. Доминантный комплекс определен по первым 2-3 позициям списка численности водорослей.
Экологическая приуроченность водорослей определена с помощью определителей, монографий [7] и крупных статей $[3,9,22]$.

Целью обсуждаемого исследования является эколого-флористический анализ фитопланктона реки Обь в створе города Сургута.

\section{Результаты исслеАования \\ и их обсужАение}

В условиях летне-осеннего периода 2019 г. максимальный прогрев верхнего слоя воды реки Обь отмечен в конце июля - плюс $19.4{ }^{\circ} \mathrm{C}$, минимальный в начале октября - плюс $11.34{ }^{\circ} \mathrm{C}$. Показатель активности водородного показателя находился в диапазоне 6.56.7, что свидетельствует о нейтральной среде верхнего слоя воды реки Обь. После весеннего подъема 2019 г., в июле уровень воды находился на отметке - 5.07 м, постепенно падая к концу сентября до 1.39 м, осенний подъем уровня реки в начале зарегистрирован вначале октября (1.45 м).

В результате изучения 27 проб фитопланктона выявлено 324 представителя водорослей, вошедших в состав 111 родов, 57 семейств, 29 порядков, 15 классов, 9 отделов (табл. 1).

Характеризуя представленность отделов в фитопланктоне Оби следует подчеркнуть, что основу составляют диатомовые - 35,2\% списочного состава выявленных водорослей и зеленые - 25,9\%, что является характерной чертой голарктических рек [16]. Пики видового разнообразия фитопланктона приходятся на конец июля 70 видов $(31,8 \%)$ при температуре воды $15^{\circ} \mathrm{C}$, третью часть, разнообразия составляют диатомовые и сентябрь - 73 (25,5\% выявленных водорослей) при 
Таблица 2. Сравнение альгоценозов планктона крупных рек России

\begin{tabular}{|l|l|l|l|l|l|}
\hline Сравниваемые показатели & Обь & Иртыш & Лена & Днепр & Волга \\
\hline Число семейств & 57 & 56 & 58 & 105 & 105 \\
\hline Число родов & 111 & 347 & 106 & 271 & 307 \\
\hline Число видов & 324 & 401 & 222 & 1569 & 1423 \\
\hline Отношение числа семейств к числу родов, $\%$ & 51,4 & 16,1 & 55,0 & 39,0 & 34,0 \\
\hline Отношение числа семейств к числу видов, $\%$ & 17,6 & 14,0 & 26,0 & 7,0 & 7,4 \\
\hline Отношение числа родов к числу видов, $\%$ & 34,3 & 87,0 & 48,0 & 17,2 & 22,0 \\
\hline Пропорции флоры & $1: 1,9: 5,7$ & $1: 6,1: 7,1$ & $1: 1,8: 4$ & $1: 2,6: 15$ & $1: 3: 14$ \\
\hline Родовая насыщенность & 2,9 & 7,1 & 4,0 & 15,0 & 14,0 \\
\hline Семейства с одним видом & 22 & 16 & 18 & 26 & 110 \\
\hline Число родов с одним видом & 56 & 60 & 49 & & 49 \\
\hline
\end{tabular}

температуре воды $11{ }^{\circ} \mathrm{C}$, основу фитопланктона в этот период составляют диатомовые и зеленые.

Как правило, в реках, текущих на север, на первом месте стоит отдел диатомовых, в отличие от многих рек, несущих свои воды на юг, в которых отмечают значительное преобладание зеленых, например, в Днепре [13].

У зеленых водорослей наибольшее разнообразие выявлено со второй половины августа до середины сентября включительно, при низких уровнях воды температуре $15-16{ }^{\circ} \mathrm{C}$. Эвгленовые занимают в крупных сибирских реках 4-5 место [11], однако в рассматриваемом случае они находятся на 3-м месте. Наибольшее их разнообразие обнаружено во II декаде июля и в сентябрьских сборах, соответственно 10 и 13-18 видов, при температуре воды в диапазоне $15,5-11,4{ }^{\circ} \mathrm{C}$. Отдел золотистых занимает 4-ую позицию, наибольшее разнообразие (6-10 водорослей) наблюдается в планктоне co II декады августы по II декаду сентября, при температуре воды 16,3-12,3․ Подобные наблюдения отмечены в реке Вах [17]. Роль остальных 5 отделов составляет в сумме 32 таксона, или 9,9\% и для фитопланктона Оби не играет большой роли, в то же время дальнейшие исследования могут изменить наше представление о роли того или иного отдела. Водоросли Xantophyta в речных водах Обского бассейна развиваются аллохтонно, о чем свидетельствуют литературные публикации [18].

Семейственный спектр водорослей, характеризует внутреннюю структуру альгофлоры исследуемого водоема. В первую десятку, отражающим основную часть флористического спектра семейственного спектра фитопланктона Оби входят 194 вида, составляя более половины всех выявленных водорослей. Лидируют семейства Scenedesmaceae (36 видов), Phacaceae (32), Dinobryaceae (31), Euglenidae (25), Bacillariaceae (15), Naviculaceae и Gomphonemataceae (nо 12), Stephanodiscaceae (11), Hydrodictyaceae и Selenastraceae (по 10).

В списке ведущих семейств первую позицию занимают эвгленовые водоросли (17,6\% всего списочного состава), затем следуют зеленые $(17,35)$, затем диатомовые $(15,4)$ и золотистые - 9,6\%. Известно, что особенностью альгофлоры высоких широт является наличие большого числа маловидовых семейств [19, 20, 22, 23]. В исследуемом фитопланктоне выявлен высокий удельный вес маловидовых семейств: представленных только одним видом - 6,8\%, или 22 семейства, 2-мя видами 6,2\%, или 10 семейств и 3-мя видами 4,6\%, или 5 семейств. Остальные семейства занимают промежуточное положение с составом от 4 до 7 водорослей.

Анализ родового спектра фитопланктона показывает, насколько неравномерно распределяются виды среди родов. Первые 8 ведущих родов, включают 33,3\% выявленных водорослей. К ним относятся Trachelomonas и Lepocinclis (по 18 видов), Desmodesmus (15), Phacus и Nitzschia (по 14), Dinobryon (12), Scenedesmus (9), Pseudokephyrion (8)

В списке лидирующих родов выделяются эвгленовые, составляя 15,3\% из числа найденных водорослей, зеленые - 7,4 и золотистые - 6,2\%. К одновидовым относится 56 родов, или 17,3\% обнаруженных водорослей, родам с 2-мя видами - 28, или 16,1\%, с 3-мя - 3, или 2,8\%. Остальные роды занимают промежуточное положение, включая 4-7 представителей.

Для флористического анализа изучаемого фитопланктона важно оценить и сравнить некоторые показатели сообществ с другими реками (табл. 2).

При сравнении фитопланктона Оби с другими крупными реками отмечается, что число семейств, родов, видов, родовая насыщенность, значительно ниже в си- 
бирских реках. Лимитирующими факторами для развития фитопланктона являются высокие скорости течения, неблагоприятный температурный режим, низкая минерализация и бедность биогенными элементами, что свойственно рекам, несущим свои воды на север.

Если в рассматриваемом ряду составов фитопланктонов - ряду обеднения - сравнивать изменение двух показателей: числа родов и среднего числа видов, разновидностей и форм водорослей в одном роде, то придется констатировать, что обеднение фитопланктонов особо проявляется в уменьшении разнообразия родов и семейств и менее резко в уменьшении второго показателя. Более богатые флоры отличаются повышенными значениями пропорции флор.

Во всех сравниваемых сообществах не высок удельный вес семейств и особенно родов, представленных только одним видом. Так для Оби он составляет 17,3\%; Иртыша - 14,6; Лены - 22,1; Днепра - 7,0; Волги $3,4 \%$. Полученные материалы, несмотря на многие черты сходства, с большой убедительностью отражают разные пути исторического развития сибирских и европейских альгофлор. Среди сибирских рек состав фитопланктона Оби является достаточно богатым.

На протяжении всего периода летне-осенних исследований в планктоне постоянно наблюдали 2 вида. Численность Aulacoseira italica (Ehrenberg) Simonsen колебалась в диапазоне от 477,7 в августе до 1267,4 тыс. кл/л в сентябре. Наибольшая численность Trachelomonas hispida (Perty) F. Stein отмечена в сентябре - 1924,9 тыс. кл/л, с быстрым ее снижением в октябре до 57,6. В более ранних исследованиях фитопланктона рек региона отмечаются подобные наблюдения $[11,15]$.

Сезонная динамика численности фитопланктона на исследуемом участке р. Обь указывает на то, что наиболее важную роль играют эвгленовые, диатомовые, зеленые и золотистые водоросли.

Общая численность водорослей в июле составляет 8533,4, тысяч клеток на 1 л воды (далее тыс. кл/л), в августе - 4358,8, сентябре - 20774,3, в октябре 1918,4 тыс. кл/л. Таким образом, кривая численности водорослей имеет 1 пик, в связи с увеличением температуры воды в первой декаде сентября, в октябре следует резкое падение численности водорослей. Всего за период исследований водоросли Cyanobacteria составили 931,9 тыс. кл/л, Chrysophyta - 5805,2, Bacillariophyta - 8824,7, Euglenophyta - 12215,2, Dinophyta - 843,0, Chlorophyta - 6965,0 тыс. кл/л. Водоросли Xanthophyta и Cryptophyta в течение летне-осеннего периода наблюдений встречаются единично.
По географической принадлежности основу фитопланктона составляют космополиты - 118 видов (35\% выявленных водорослей), что является характерным для многих северных регионов. По количеству космополитных видов зеленые занимают лидирующую позицию - 39 видов (21\%). По категории галобности, наиболее многочисленными является группа индифферентных водорослей, которая включает в себя 226 видов (69,8\%), что свидетельствует о малой минерализации вод, обусловленной физико-географическими особенностями исследуемой территории. По отношению к активности водородного показателя среды обитания водорослей первое место занимают индифферентные виды 154 вида (45\%). Воды р. Обь в районе г. Сургут имеют нейтральную реакцию, несущественно изменяющуюся в течение года, поэтому в реке выявлена значительная доля индифферентов. Из них с наибольшей численностью развиваются зеленые водоросли. По отношению к концентрации органических веществ состав водорослей-индикаторов образован - мезосапробами, включающими 186 видов (55\%). Это говорит о средней степени загрязнения вод легкоокисляемыми органическими нетоксичными веществами. Воды р. Обь самоочищаются, но слабо насыщены кислородом.

Сохранение биоразнообразия занимает особое место среди основных экологических проблем современности. Проведение идентификации и инвентаризации видового состава водной экосистемы реки Обь указывает на богатый водорослей состав планктона. По сравнению с данными 1995 года видовой состав альгоценоза в районе г. Сургут на 173 вида уменьшился. Возможно, этот факт связан с тем, что результаты предыдущих исследований относятся к многолетним в отличие от настоящих. Однако, в среднем течении Оби нами выявлено 239 новых видов, часть которых в 1994 г. были выявлены выше по течению, что свидетельствует о смене биогеоценозов. Пропорция флоры для р. Обь в районе г. Сургут по оригинальным данным составляет 1:1,9:5,7. Число одновидовых семейств в семейственном спектре составляет $38.6 \%$; в родовом спектре число одновидовых родов составляет - 50.5\%. Наиболее устойчивыми видами для реки оказались Aulacoseira italica (Bacillariophyta) и Trachelomonas hispida (Euglenophyta), у которых отмечена наиболее высокая активность. Пик общей численности водорослей приходится на сентябрь - 20774.3 тыс.кл/л. По количеству клеток на 1 литр воды выделяются отделы Bacillariophyta и Euglenophyta. Экологический анализ водорослей фитопланктона Средней Оби показал преобладание планктонных, широко распространенных форм, олигогалобных, бетамезосапробных разновидностей и форм водорослей, предпочитающих нейтральную реакцию среды. 


\section{ЛИТЕРАТУРА}

1. Ашурова 3.М., Скоробогатова 0.Н. Зеленые водоросли планктона реки Обь в районе города Сургут // Бюллетень науки и практики. 2019. Т. 5. № 8. C. 8-16.

2. Баженова 0.П. Многолетняя динамика фитопланктона бассейна реки Иртыш: Состояние и тенденции. Омск, 2005, 318 с.

3. Баринова С.С., Медведева Л.А. Водоросли-индикаторы в оценке качества окружающей среды. М.: ВНИИприроды, 2000. 150 с.

4. Болота Западной Сибири, их строение и гидрологический режим / Под ред. Николаева. Л.: Гидрометеоиздат, 1976. 448 с.

5. Гонтажевская Е.Н., Скоробогатова 0.Н. Пространственное распределение хлорококковых водорослей в прибрежном планктоне реки 0бь // В сборнике: XX Всероссийская студенческая научно-практическая конференция Нижневартовского государственного университета. Ответственный редактор А.В. Коричко. 2018. С. 85-89.

6. Изгужина Р.Р., Скоробогатова 0.Н. Динамика водорослей Scenedesmaceаe в прибрежном планктоне реки 0бь // В сборнике: XX Всероссийская студенческая научно-практическая конференция Нижневартовского государственного университета. Сборник статей. Ответственный редактор А.В. Коричко. 2018. С. 104-108.

7. Корнева Л.Г. Фитопланктон водохранилищ бассейна Волги / Под ред. А.И. Копылова. Кострома: Костромской печатный дом. 2015.284 с.

8. Малышев Л.И. Флористические спектры Советского Союза // История флоры и растительности Евразии. Л., 1972. С. 17-40.

9. Науменко Ю.В. Водоросли фитопланктона реки Оби. Препринты ИПМ им. М.В. Келдыша. 1995. С. 55.

10. Науменко Ю.В. Фитопланктон реки Оби автореферат дис. ... доктора биологических наук / Центр. сиб. ботанич. сад. Новосибирск, 1996.

11. Науменко Ю.В., Скоробогатова 0.Н. Эвгленовые водоросли р. Вах (Западная Сибирь). Вестник экологии, лесоведения и ландшафтоведения. 2010. № 10. C. 49-53.

12. Обзор состояния окружающей среды города Сургута 2006-2010, 2011. 98 с.

13. Приймаченко А.Д. Фитопланктон и первичная продукция Днепра и днепровских водохранилищ. Киев: Наук, думка, 1981. 278 с.

14. Садчиков А.П. Методы изучения пресноводного фитопланктона: методическое руководство. М., 2003. 157 с.

15. Скоробогатова 0.H. Aulacoseira italica (Ehr.) Sim. в планктоне реки Вах (Западная Сибирь). Естественные и технические науки. 2010. № 3 (47). С. 107111.

16. Скоробогатова 0.Н. Фитопланктон р. Вах (Западная Сибирь) диссертация на соискание ученой степени кандидата биологических наук / Центральный сибирский ботанический сад Сибирского отделения Российской академии наук, г. Новосибирск. Нижневартовск, 2010.

17. Скоробогатова 0.Н. Редкие Crysophyta в планктоне реки Вах и условия их обитания. В мире научных открытий, № 4.1(64) г. Красноярск: Научно инновационный центр, 2015. С. 670-679.

18. Скоробогатова 0.Н. Эколого-таксономические сведения о водорослях Xantophyta в планктоне реки Вах В мире научных открытий, № 4.1(64) г. Красноярск: Научно инновационный центр, 2015а. С. 661-670.

19. Скоробогатова 0.Н. Таксономическая структура цианопрокариот и водорослей водных объектов парка Югра (Нижневартовский район, ХМАО Югра). Вестник Нижневартовского государственного университета. 2017. № 4. С. 8-16.

20. Скоробогатова 0.Н., Мингалимова А.И., Галимзянова С.Т. Таксономический Состав водорослей р. Аган // В сборнике: Север России: стратегии и перспективы развития. Материалы II Всероссийской научно-практической конференции. 2016. С. 281-286.

21. Шмидт В.М. Математические методы в ботанике. Л: Изд-во Ленингр. Ун-та. 1984. 288 с.

22. Skorobogatova 0.N. Taxonomic Composition of phytoplankton in the Vakh river (Western Siberia) // В сборнике: IOP Conference Series: Earth and Environmental Science. 5th International field symposium "West Siberian Peatlands and Carbon Cycle: Past and Present" and the International conference "Carbon Balance of Western Siberian Mires in the Context of Climate Change". 2018. C. 012017.

23. Skorobogatova 0.N., Yumagulova E.R., Storchak T.V., Ivanova N.A. Phytoplankton of surface waters under oil pollution (Samotlor field, Western Siberia). Periodico Tche Quimica. 2019. T. 16. № 32. C. 306-320.

24. Guiry M.D. in Guiry, M.D. \&Guiry, G.M. 2019. AlgaeBase. World-wide electronic publication, National University of Ireland, Galway. http://www.algaebase.org; searched on 08 June 2019.

(с) Скоробогатова Ольга Николаевна (Olnics@yandex.ru ),

Гонтажевская Екатерина Николаевна, Москалева Анна Сергеевна.

Журнал «Современная наука: актуальные проблемы теории и практики» 